
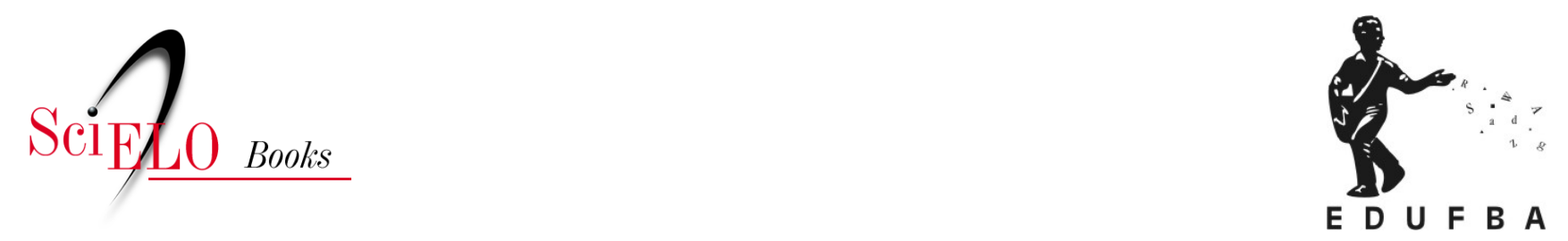

\title{
Potencialidades e limites das tecnologias na promoção dos direitos humanos de crianças e adolescentes
}

\author{
Rodrigo Nejm
}

\section{SciELO Books / SciELO Livros / SciELO Libros}

NEJM, R. Potencialidades e limites das tecnologias na promoção dos direitos humanos de crianças e adolescentes. In: RIBEIRO, J.C., FALCÃO, T., and SILVA, T. orgs. Midias sociais: saberes e representações [online]. Salvador: EDUFBA, 2012, pp. 249-269. ISBN 978-85-232-1734-1. Availablefrom: doi: 10.7476/9788523217341.014. Also available in ePUB from: http://books.scielo.org/id/hcmrr/epub/ribeiro-9788523217341.epub

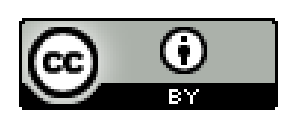

All the contents of this work, except where otherwise noted, is licensed under a Creative Commons Attribution 4.0 International license.

Todo o conteúdo deste trabalho, exceto quando houver ressalva, é publicado sob a licença Creative Commons Atribição 4.0. 


\section{Potencialidades e limites das tecnologias na promoção dos direitos humanos de crianças e adolescentes}

Rodrigo Nejm

Sabemos que as Tecnologias da Informação e Comunicação (TIC) têm sido intensamente incorporadas à vida das pessoas na atualidade, mediando os mais variados tipos de interação social desde a primeira infância. Nas últimas cinco décadas, assistimos a intensas e rápidas mudanças nas TIC, cada vez mais integradas (convergência), potentes e em vias de massificação. Além de mudarem muito rapidamente, estes dispositivos tecnológicos têm sido incorporados também com muita velocidade nas famílias e instituições brasileiras, implicando importantes efeitos na produção das subjetividades na contemporaneidade. Com todas as nossas contradições e radicais desigualdades sociais, nós brasileiros também presenciamos este processo global de incorporação das TIC nas atividades cotidianas, das mais banais às mais complexas, nos diferentes estratos sociais e faixas etárias. Parecenos importante destacar alguns efeitos deste processo no cotidiano das atuais gerações de crianças e adolescentes que, cada vez mais cedo, têm suas interações sociais mediadas pelas TIC. Ao considerarmos as TIC como dispositivos cada vez mais decisivos no processo de produção das subjetividades, buscamos refletir sobre as potencialidades e limites destes dispositivos na promoção dos direitos humanos das crianças e adolescentes "nativos digitais". 


\section{Lugares das tecnologias na infância e adolescência}

Para fazer esta reflexão, precisamos reconhecer que presenciamos profundas mudanças psicossociais na infância e na adolescência, mudanças produzidas por muitos fatores, dentre eles, mas não apenas, pelo uso intenso e diverso das TIC. Reconhecemos ainda que a própria noção de "nativos digitais" (e suas variações: "geração digital"; "Geração X, Y, Z...”) carrega em si muito mais a retórica de um discurso performativo-preditivo do que descritivo, como enfatizam as críticas de Buckingham (2008) e Bruno (2008). Em muitas abordagens, é forte o determinismo que superestima a participação das TIC nas transformações da infância e da adolescência, destacando as mudanças cognitivas, as novas formas de aprendizagem, de lazer e de socialização.

Em última análise, assim como outras formas de marketing retórico, o discurso sobre as "gerações digitais" é justamente uma tentativa de construção do objeto sobre o qual se pretende falar. Ele não representa uma descrição do que crianças e jovens são atualmente, mas um conjunto de imperativos sobre o que eles deveriam ser ou sobre o que precisam se tornar. ${ }^{1}$ (BUCKINGHAM, 2008, p. 15, tradução nossa)

Certamente as TIC desempenham um papel de destaque na transformação do lazer, do estudo, do comunicar e do brincar das novas gerações, mas para seguir nossa reflexão sobre as potencialidades e limites das TIC na promoção dos direitos humanos de crianças e adolescentes, reconhecemos que há uma multiplicidade de outros dispositivos que operam transformaçóes na infância e precisamos relativizar o determinismo tecnológico. Encaramos aqui as próprias noções de

1 "Ultimately, like other forms of marketing rhetoric, the discourse of the "digital generation" is precisely an attempt to construct the object of which it purports to speak. It represents not a description of what children or young people actually are, but a set of imperatives about what they should be or what they need to become." 
infância e adolescência como noções sócio e historicamente construídas através de diferentes dispositivos que produziram (e produzem) discursos de verdade e regimes de poder sobre a vida das crianças e adolescentes. Em cada momento histórico e em cada contexto social podemos reconhecer dispositivos que se destacam na configuração da sociabilidade e na produção de subjetividades. (FOUCAULT, 1999) Mesmo considerando que as TIC merecem hoje um destaque em nossas análises sobre a produção das subjetividades e a promoção dos direitos humanos de crianças e adolescentes, é vital reconhecer outros importantes elementos que mudaram profundamente o lugar social destes sujeitos na história recente.

Não podemos aqui abarcar suficientemente a complexidade destas mudanças, mas podemos destacar alguns fatores que permitem uma melhor compreensão da atualidade sem deixar-nos seduzir pelo determinismo tecnológico. As atuais gerações são fruto de importantes mudanças, com destaques para: a nova subjetividade jurídica com o advento da Convenção dos Direitos das Crianças (ONU, 1989, e, no caso do Brasil, do Estatuto da Criança e do Adolescente - ECA, 1990); a entrada cada vez mais precoce num universo de consumo com produtos e intensa publicidade segmentados; a experimentação de contradições entre a erotização precoce e a repressão na expressão da sexualidade; e a conquista de maior independência em uma suposta cultura juvenil, ao mesmo tempo em que são retardadas a independência financeira e as responsabilidades da vida adulta. Como destaca Abad (2003), apresenta-se uma nova condição juvenil no mundo contemporâneo, condição relacionada:

- ao quase desaparecimento da infância - e ao consequente prolongamento da juventude, com o adiantamento precoce da adolescência e o retardamento da juventude até depois dos 30 anos; 
- às dificuldades das sociedades atuais em facilitar o trânsito da juventude pelo circuito família-escola-emprego, no mundo adulto;

- à influência dos meios de comunicação.

Como reforça Livingstone (2009), não podemos centrar a reflexão nas tecnologias sem levar em conta as outras transformações no mundo do trabalho, na estruturação da família e no universo de consumo infanto-juvenil. Assistimos a uma gradativa privatização das famílias, umas em relação às outras, e à individualização dos membros nas famílias. Esta individualização dos projetos de vida é acompanhada pela institucionalização e padronização dos estilos fornecidos pela mídia. Ao mesmo tempo em que há o reconhecimento das crianças e adolescentes como sujeitos de direitos, há a intensificação das ações de controle, regulação e vigilância sobre o comportamento destes indivíduos. (LIVINGSTONE, 2009) Na atualidade, assim como a própria condição infanto-juvenil mudou, também os meios de comunicação de massa passam por grandes mudanças com a gradativa convergência digital e ampliação do poder do usuário para criar e disseminar conteúdos.

\section{Meios, mediações e dispositivos tecnológicos}

Dentre as TIC, a internet figura como um das tecnologias que está consolidando esta convergência das mídias e radicalizando a mudança no papel dos usuários. Não podemos mais pensar nas TIC e na mídia apenas como meios de comunicação de massa que atingem um público de receptores. As TIC agrupam um conjunto de dispositivos tecnológicos diversos (tablets, computadores, celulares, televisores, filmadoras, máquinas fotográficas, rádio, livros) que se integra gradativamente nas funçôes e possibilidades de conexão no ciberespaço. Jovens filmam, fotografam, relatam e publicam on-line suas experiências 
de vida nas redes sociais, usando estes dispositivos como mediadores importantes de suas interaçôes sociais. Os meios de comunicação de massa unilaterais, como a televisão e o rádio, continuam exercendo decisiva influência, mas gradativamente adaptam-se aos novos formatos de iteratividade. No ciberespaço e na cibercultura (LEMOS; LEVY, 2010) não é mais a lógica de recepção passiva pelas massas que pode descrever os novos formatos de interações com a mídia. Mesmo no âmbito dos meios de comunicação de massa, como a televisão, o processo de recepção e produção de sentidos pelas audiências deve ser visto como dinâmico, crítico e contextualizado. Ao estabelecerem novas mediações, as tecnologias propiciam novas lógicas de produção, distribuição e consumação da matéria e das ideias. Concentrando a atenção nas mediações que procedem na recepção/interação com as mídias e no uso das TIC, estamos deslocando o eixo do debate dos meios para as mediações, "para as articulações entre práticas de comunicação e movimentos sociais, para as diferentes temporalidades e para a pluralidade de matrizes culturais", (MARTÍN-BARBERO, 2001, p. 270) que dão as condições de possibilidade da transformação da realidade social e das identidades.

Inserida nesse contexto onde coexistem diferentes temporalidades históricas e modos de mediação, as TIC tornam-se importantes agentes no processo de produção das subjetividades e hibridização das culturas contemporâneas. Esta visão dinâmica das mediações na recepção (MARTÍN-BARBERO, 2001) ajuda a dinamizar a compreensão da relação das crianças e adolescentes com as novas TIC e destacar a importância do contexto do seu uso em sociedades híbridas, complexas e desiguais como a brasileira. A recepção não pode mais ser vista como um processo redutível ao psicológico e nem ao cotidiano, já que é um processo que envolve as mais variadas questões políticas e culturais. Na proposta das mediações de Barbero (2001), o processo de recepção é configurado por uma complexa rede de relações de poder que perpassam não só as relações sociais, mas também 
a produção das identidades e a expressão dos desejos de cada usuário. Além desta perspectiva das mediações, consideramos que abordar as TIC como dispositivos na perspectiva de Foucault pode nos ajudar a evitar o determinismo tecnológico numa reflexão sobre limites e potencialidades das TIC na promoção dos direitos humanos de crianças e adolescentes.

Como dispositivos, não compreendemos as TIC exclusivamente como instrumentos de sistematização ordenada do mundo, mas acreditamos que

[...] o conceito de dispositivo parece ocupar-se do fato de que novas relações com os objetos caracterizam a sociedade contemporânea, ou que uma outra relação com o mundo material é possível, não somente sobre o modo da instrumentalização ou da alienação, mas sobre o modo de "freqüentação", do contato ou mesmo da experiência afetivo-corporal. (PEETERS; CHALIER, 1999, p. 22, tradução nossa)

Neste caso, as TIC como dispositivos não são encaradas como meros instrumentos que operam concretamente na realidade para filmar, fotografar, enviar mensagens ou baixar músicas. Especialmente no caso da internet, reconhecemos que há uma diversidade de lógicas e temporalidades compartilhando o ciberespaço e sendo frequentada pelos internautas de diferentes idades, condiçôes econômicas e culturais. Como apontado por Foucault (1999), precisamos conceber a noção de dispositivo como

[...] um conjunto decididamente heterogêneo que engloba discursos, instituições, organizações arquitetônicas, decisões regulamentares, leis, medidas administrativas, enunciados científicos, proposições filosóficas, morais, filantrópicas. Em suma, o dito e o não dito são os elementos do dispositivo. $\mathrm{O}$ dispositivo é a rede que se pode estabelecer entre estes elementos [...] (FOUCAULT, 1999, p. 244) 
Cada dispositivo tecnológico traz em si uma singularidade na forma de fazer ver e falar a realidade social na qual opera. Reconhecendo a importância da diversidade destes dispositivos, pretendemos focar nossa reflexão nas singularidades da internet como dispositivo que apresenta novas potencialidades de participação e de controle. Ao mesmo tempo em que a internet provoca uma reconfiguração da TV, do rádio, da imprensa escrita e dos demais meios ao potencializar a participação e emancipação dos usuários, sabemos que a convergência digital também traz para a internet as antigas formas de controle editorial e censura. Especialmente nas ações de combate aos crimes e violências contra crianças e adolescentes, encontramos algumas das contradições em torno da defesa e restrição de direitos humanos fundamentais.

Os dispositivos têm uma função estratégica dominante, mas atuam produzindo ressonâncias, pois cada efeito do dispositivo, desejado ou não, exige uma rearticulação dos elementos heterogêneos que o compõem. O dispositivo, nesta ótica, está sempre inscrito em um jogo de poder, "estando sempre, no entanto, ligado a uma ou a configuraçôes de saber que dele nascem mas que igualmente o condicionam. É isto, o dispositivo: estratégias de relaçôes de força sustentando tipos de saber e sendo sustentadas por eles". (FOUCAULT, 1999, p. 244) Neste sentido, consideramos que, dentre as TIC, a internet apresenta-se como um dispositivo complexo e híbrido que está produzindo ressonâncias significativas sobre a sociabilidade de crianças e adolescentes que têm suas interaçôes mediadas, desde muito cedo, pelas lógicas incorporadas neste dispositivo. Não se trata aqui de julgar o dispositivo como sendo positivo ou negativo na vida das crianças, mas refletir sobre as potencialidades deste dispositivo na afirmação de estratégias que visam a efetivação dos direitos humanos de crianças e adolescentes, ao mesmo tempo em que reconhecemos a intensificação de estratégias de vigilância e controle das subjetividades. 
O dispositivo tem um aspecto de relação com os objetos, com as palavras e com as pessoas que diz respeito à constituição das identidades, que estabelece uma mediação afetiva e corporal entre o "eu" e o mundo, entre o "eu" e o outro, e, finalmente, do "eu" consigo mesmo. (BERTEN, 1999) Na internet coabitam estratégias de massificação e singularização, compartilhamento e restrição, libertação e controle, participação e acomodação. Precisamos considerar que uma sujeição real pode nascer de uma relação fictícia (FOUCAULT, 2004) e, assim, precisamos estar atentos a todas as manobras legais, corporativas e civis que pretendem regular a internet, já que cada movimento traz consigo um modelo de governança sustentado por um conjunto de saberes específicos.

Mesmo que tenhamos feito as ressalvas sobre o determinismo tecnológico na reconfiguração da sociabilidade de crianças e adolescentes, os discursos prescritivos sobre as "gerações digitais" acabam sujeitando não apenas as novas gerações, mas uma variedade de instituiçôes que se ocupam da formação e cuidado. As escolas, as famílias e as políticas públicas de proteção são chamadas a atender esta nova realidade da infância que se supõe radicalmente diferente por ser digital. Justamente neste ponto merece atenção a análise sobre a promoção dos direitos humanos em tempos de relações sociais intensamente mediadas pelas TIC. Se por um lado precisamos compreender as violações de direitos que são intensificadas pelas novas TIC, como internet e celulares, as TIC podem ser dispositivos extremamente potentes na efetivação de direitos, como participação, liberdade de expressão e construção progressiva da autonomia de crianças e adolescentes. A internet, por exemplo, é um importante espaço de possibilidade para novos ritos de passagem, experimentações emocionais e sexuais, singularização das subjetividades e para balancear as rebeldias e conformações da adolescência. (LIVINGSTONE, 2009)

Uma maneira relevante de promover estes espaços de singularização das subjetividades é justamente proporcionando uma educação 
em direitos humanos também no que diz respeito às TIC, atenta às armadilhas dos dispositivos. A mesma internet que opera como rede de controle e vigilância pode operar como espaço possível de libertação, participação e compartilhamento sem precedentes nas mesmas "gerações digitais".

Os atuais movimentos de participação e colaboração são alvo de uma série de embates, dada a sua potencialidade na abertura de novas formas de fazer política, arte, conhecimento e cultura. Não por acaso, é exatamente aí que investem as próprias vias do controle, procurando capitalizá-los em seu favor. Identificar e problematizar as relaçôes entre vigilância e participação é fundamental para desviar esse potencial do destino policial que lhe reserva uma das faces do impulso participativo na cibercultura”. (BRUNO, 2009, p.13)

Neste sentido é que precisamos refletir sobre o equilíbrio possível entre a afirmação de direitos e o combate aos cibercrimes contra crianças e adolescentes, já que é justamente em nome da proteção de crianças que muitas estratégias de controle policial e corporativo buscam suas legitimidades.

\section{Entre riscos e oportunidades}

Para nossa reflexão sobre os limites e potencialidades das TIC na promoção dos direitos humanos de crianças e adolescentes, podemos partir da análise de situações recorrentes de violações de direitos e "riscos" que são frequentemente apontadas pela imprensa e têm com palco a própria internet. Neste caso, nos limitaremos às situações do chamado ciberbullying e do sexting. $\mathrm{O}$ uso das terminologias em inglês já atesta o caráter global destes fenômenos na vida das crianças e adolescentes urbanos do planeta. Sabemos que a exclusão digital ainda é bastante expressiva não apenas na possibilidade de acesso, mas também no tipo de mediação e suporte no qual o acesso ocorre. Mesmo 
que a alfabetização digital se dê em diferentes graus em cada contexto socioeconômico e cultural, a especificidade das interaçôes digitais tem ganhado força e gerado implicações diretas e indiretas nas mais variadas instituiçôes, especialmente nas famílias (através dos conflitos geracionais que provoca), nos ambientes de trabalho (através das novas temporalidades que produz) e nas escolas (através das novas relações possíveis com o compartilhamento das informações e as produções coletivas do conhecimento). Considerando que as novas situações de risco mobilizam as instituições e os sujeitos para produzirem discursos e saberes que apropriem estas novas manifestações, partiremos destes dois fenômenos específicos (ciberbullying e sexting) para discutir sobre a violação e promoção de direitos humanos de crianças e adolescentes na internet e suas implicações na produção das subjetividades.

Compreendendo a dimensão pública da internet podemos entender que no ciberespaço temos a expressão dos mais variados comportamentos, assim como em tantos outros espaços públicos de relacionamento. Ao tornar-se palco de grande parte das interaçôes sociais de crianças e adolescentes, a internet também explicita faces da violência. Exemplos desta violência são as novas dimensões que as antigas práticas de agressão e intimidação entre crianças na escola (bullying) ganharam quando as mensagens e comportamentos ofensivos são expostos a milhares de espectadores através dos sites de compartilhamento de vídeos, fotos e textos. Crianças e adolescentes são humilhados diante de um enorme público que envolve familiares, amigos, vizinhos e um universo quase ilimitado de internautas que podem ter acesso às cenas vexatórias divulgadas por algum colega, configurando o chamado ciberbullying. Isto que parece apenas uma brincadeirinha, aos olhos dos que praticam / divulgam / consomem, pode produzir graves consequências às vítimas e ilustra uma sociabilidade repleta de intolerância e competitividade que tem acompanhado o desenvolvimento das "gerações digitais". Não bastasse a violência contida nesta prática que se dissemina dentro e fora das escolas (desde muito antes 
da internet), presenciamos uma ampla banalização do uso dos termos bullying e ciberbullying. Os termos estão sendo usados indiscriminadamente para descrever uma infinidade de formas de violências. Se o termo surge para diferenciar as formas de violência entre pares (crianças e adolescentes), atualmente até deputados usam o termo bullying para descrever supostas calúnias e injúrias sofridas através da imprensa, um sinal do esvaziamento deste termo já tão problemático.

O ciberbullying, como manifestação digital deste tipo de violência entre pares, ganhou destaque na imprensa massiva e vem sendo apropriado também pelo discurso psiquiátrico, que identifica nele sintomas e causas de transtornos de personalidade em crianças, numa perigosa redução desta violência a patologias. Noutra medida, os casos mais violentos de bullying praticado pela internet alimentam também os discursos a favor da minoridade penal que exigem punições mais severas aos pequenos "bandidos". O que nos interessa aqui não é explorar as variações dos conceitos de ciberbullying e bullying, nem mesmo testar sua validade, mas sim destacar o quanto este tipo de violência (independentemente do nome atribuído) pode ilustrar os reflexos de uma sociabilidade marcada pela intolerância à diversidade, pela privatização dos interesses coletivos e pelo imperativo da competição que promovemos desde cedo às nossas crianças e adolescentes. Intolerância, individualismo e competitividade são referências de uma sociabilidade marcada pelas intensas e históricas violações aos diretos direitos humanos que persistem até nesta geração de crianças e adolescentes que presencia as comemorações dos 21 anos do Estatuto da Criança e do Adolescente (ECA), no Brasil, em 2011. Como veremos em seguida, certamente há avanços jurídicos e institucionais, mas ainda carecemos de uma mudança mais consolidada no que diz respeito à incorporação dos direitos humanos como mediadores das interações sociais cotidianas, desde a educação na primeira infância.

Outro fenômeno recente e que merece destaque nas gerações digitais é o sexting, nome dado às praticas de adolescentes que tiram fotos 
do próprio corpo nu ou seminu e enviam para amigos e pretendentes através de mensagens de celular e/ou na internet. Em muitos casos, o(a) adolescente perde o controle sobre a imagem, que ganha a rede e pode vir a ser exposta ou comercializada em sites de pornografia infanto-juvenil. Esta prática viola os artigos 241 - A, B e E do ECA, mas traz à tona um complexo cenário de reconfiguração das fronteiras entre público e privado e das formas de cuidado de si nestas novas gerações. Estes fenômenos podem nos apontar paisagens de uma subjetividade produzida na exterioridade das relações sociais mediadas e espetacularizadas.

Onde os dispositivos modernos de visibilidade escavavam uma subjetividade interiorizada que, a partir do olhar do outro, instaurava a auto vigilância, hoje parece estar se constituindo uma subjetividade exteriorizada, onde as esferas de cuidado e controle de si se fazem na exposição pública, no alcance do olhar, escrutínio ou conhecimento do outro. $\mathrm{O}$ decisivo aqui é compreender que não se trata da exteriorização de uma interioridade que, já tendo se constituído, decide se expor, mas antes de uma subjetividade que se constitui no ato mesmo de se fazer visível ao outro, portanto, como exterioridade. (BRUNO; PEDRO, 2005, p.13)

O sexting traz à tona uma condição da sexualidade reificada, espetacularizada, midiatizada ou apenas a livre expressão da sexualidade? Em tempos de hiper conexão, quais critérios para descrever a condição peculiar de uma pessoa em desenvolvimento que devem ser respeitados para delimitar os direitos de privacidade e de acesso à informação, cultura e lazer para crianças e adolescentes na internet? Em tempos em que a mídia sensacionalista reclama do excesso de direitos para os adolescentes, o que fazer quando o ato infracional é praticado 
contra si mesmo (neste caso, a violação voluntária do Art. 241-E do $\mathrm{ECA}^{2}$ )? Em uma sociedade que produz e consome cada vez mais a erotização precoce da infância, seja na música, na televisão, na moda ou na internet, quais critérios sustentam os limites de idade de consentimento para relaçóes sexuais na adolescência? Numa sociedade ainda marcada pelo tabu na questão do desenvolvimento e expressão da sexualidade infanto-juvenil e pela pedofilização, como promover os direitos sexuais e reprodutivos das crianças e adolescentes?

Neste contexto complexo de indagações, é vital um olhar sobre os limites e potencialidades dos direitos humanos de crianças e adolescentes previstos em lei como prioridade absoluta (Constituição Federal, Art. 227), e é também necessária uma preocupação com os artigos do ECA que garantem às crianças e adolescentes a liberdade de expressão, o direito à privacidade e o direito de acesso ao lazer e à cultura. Precisamos ter em mente que crianças e adolescentes são, antes de tudo, sujeitos de direitos e não apenas objetos de ações de proteção. Crianças como sujeitos de direitos fazem repensar o papel dos adultos e as relações de poder que podem ou não favorecer a consolidação gradativa da autonomia, especialmente no campo do exercício da sexualidade no qual imperam a proteção paternalista e o tabu. (MELO, 2008)

Muito mais do que prevenir o ciberbullying e o sexting com novas estratégias de controle sobre a navegação das crianças e adolescentes, precisamos evidenciar a construção compartilhada da autonomia progressiva para que crianças e adolescentes possam ser sujeitos de seus direitos também na cibercultura. Neste sentido, as TIC podem atuar como dispositivos que favorecem espaços de libertação, de com-

\footnotetext{
2 Art. 241-E do Estatuto da Criança e do Adolescente: "Para efeito dos crimes previstos nesta Lei, a expressão 'cena de sexo explícito ou pornográfica' compreende qualquer situação que envolva criança ou adolescente em atividades sexuais explícitas, reais ou simuladas, ou exibição dos órgãos genitais de uma criança ou adolescente para fins primordialmente sexuais". (Incluído pela Lei no 11.829 , de 2008)
} 
partilhamento de valores fora do padrão hegemônico e de exercício de uma cidadania menos tutelada. Como sujeitos de direitos, crianças e adolescentes não podem ser apenas receptores passivos de ajudas, assistencialismos ou protecionismos dos adultos ou das políticas públicas. Proteger, dentro ou fora da internet, traz à tona o desafio de equilibrar o exercício dos direitos à privacidade, à liberdade e ao acesso à informação com os limites previstos para respeitar a singularidade de cada fase do desenvolvimento e maturidade das crianças e adolescentes. $\mathrm{Na}$ internet este desafio se torna ainda mais complexo com fronteiras, limites e representaçôes cada vez mais fluidas e dinâmicas. Como definir faixas etárias para conteúdos on-line? Como avaliar e acompanhar o tipo de conteúdo produzido e compartilhado com os pares? Como promover uma consciência crítica para que os adolescentes façam escolhas responsáveis em sua navegação pelo mar de possibilidades no ciberespaço?

Indagações como estas estão na base de muitas iniciativas focadas na promoção dos direitos humanos de crianças e adolescentes, mas as possíveis respostas serão sempre incompletas, provisórias e complexas. Acreditamos que a compreensão das TIC como dispositivos e a leitura atenta das relações de força que expressam podem ser um primeiro passo no sentido de ampliar os espaços e experiências que favorecem a emancipação e a singularização das subjetividades na cibercultura, um caminho contra-hegemônico e que busca, no respeito à diversidade, escapar à reprodução de estilos de vida massificados e relaçôes sociais cada vez mais individualizadas.

A fala do diretor da Google, Eric Schmidt, em entrevista dada ao Wall Street Journal em 2010, acaba ilustrando uma das abordagens possíveis sobre os valores que guiam a navegação on-line de crianças e adolescentes na atualidade. Schmidt deixou escapar uma ideia tão interessante quanto assustadora ao afirmar que talvez as pessoas devessem mudar seus nomes ao atingir a vida adulta para erradicar 
possíveis danos à reputação causados pelas buscas em registros armazenados nas redes sociais.

'Eu não acredito que a sociedade entenda o que acontece quando tudo está disponível e pode ser acessado por todo mundo, todo o tempo', disse Schmidt, que prevê - aparentemente, de forma séria - que todo jovem um dia será levado a mudar automaticamente de nome ao atingir a idade adulta, para deixar de ser apontado como responsável por suas aventuras de garoto ou garota registradas em sites de mídia social, informa o Wall Street Journal. ${ }^{3}$

Esta declaração, por mais que deva ser contextualizada para limitar suas interpretaçóes, não deixa de atestar uma concepção que admite a história de vida on-line como mero acessório, como uma roupa que podemos vestir e trocar de acordo com os interesses do momento. Há nesta abordagem uma radicalidade da liberdade de expressão que ignora o senso de responsabilidade dos discursos e perfis nesta nova esfera pública que é o ciberespaço. Sem poder aprofundar esta questão crucial da configuração da esfera pública política do ciberespaço e a força das discursividades que nela circulam, podemos reconhecer que a dimensão pública da internet precisa ser reconhecida pelos adolescentes como espaço legítimo de participação com respeito aos deveres e direitos implícitos nas sociedades pretensamente democráticas. Considerar que a própria história de vida, com suas experimentações arriscadas e intensas da adolescência, pode ser refeita como refazemos perfis nas redes sociais nos indica uma subjetividade simulada para servir a uma performance pontual e espetacularizada. (BRUNO, 2008)

Para garantir uma educação que promova a afirmação de direitos e a emancipação, precisamos rever reducionismos que desqualificam

3 Notícia Publicada em 18 de agosto de 2010, às 08h35, no IDG Now, disponível em: <http:// idgnow.uol.com.br/seguranca/2010/08/18/ceo-da-google-aconselha-mudar-de-nome-paraescapar-a-bisbilhotice-na-web>. Acessada em: 05 ago. 2011. 
a voz e a vontade de crianças e adolescentes em nome de uma suposta proteção, mas também equilibrar liberdade com responsabilidade nas experimentações on-line. A internet permite um fantástico empoderamento dos usuários, e este empoderamento só será emancipador quando for mediado por valores e compromissos éticos, respeitando a diversidade de vozes e garantido dignidade às subjetividades que escapam dos modelos prescritos pelo mercado de celebridades que tanto seduzem crianças e adolescentes. No entanto, se este modelo prescritivo de culto às celebridades e culto ao individualismo extremo continuar sendo reafirmado como valor pelos adultos-pais e pela mídia massiva, dificilmente esta "geração digital" poderá efetivamente ter nas TIC um espaço de mudanças radicais na sua sociabilidade. Pensar em direitos humanos de crianças e adolescentes não pode estar associado apenas à repressão e proteção tutelar, mas especialmente a ações educativas que possibilitem a experimentação da diversidade e da liberdade enquanto compromissos coletivos e não apenas direitos individuais. ${ }^{4}$ Estes são caminhos possíveis para termos as TIC operando na singularização das subjetividades, considerando que

[...] ela (a subjetividade) é essencialmente social, e assumida e vivida por indivíduos em suas existências particulares. $\mathrm{O}$ modo pelo qual os indivíduos vivem esta subjetividade oscila entre dois extremos: uma relação de alienação e opressão, na qual o indivíduo se submete à subjetividade tal como a recebe, ou uma relação de expressão e de criação, na qual o indivíduo se reapropria dos componentes da subjetividade, produzindo um processo que eu chamaria de singularização [...]. (GUATTARI, 1992, p. 33)

4 O Brasil mostra avanços ao construir um Plano Nacional de Educação em Direitos Humanos que, desde sua concepção, prevê um campo de açôes específicas no eixo Mídia e Educação, apesar de a percepção de mídia ainda estar focada nos efeitos "negativos" das mídias massivas, como rádio, televisão, jornais e revistas. 
A educação em direitos humanos pode ser fortalecida pelas pesquisas em Psicologia e demais ciências humanas quando está associada a uma compreensão que apreende a subjetividade como diversidade, mudança e devir. Pensar a efetivação do direito à dignidade na diversidade é consolidar processos de subjetivação que não se limitem à reprodução de estilos de vida pré-formatados para serem consumidos em massa nas telas do cinema, nas telenovelas, nas colunas sociais ou nas navegações definidas pelos filtros algorítmicos regidos pela publicidade no ciberespço. ${ }^{5}$ A reprodução em si não é o problema e, pelo contrário, está na base das organizações sociais complexas que produzem e compartilham cultura, mas quando a reprodução se torna imperativa e passa a ser controlada para absorver, codificar e repelir as diferenças, colocamos em risco a vitalidade da diversidade e suprimimos a dignidade do diferente.

Podemos aqui falar em subjetividade apreendida em sua dupla face (GUATTARI, 1992; ROLINK, 1997): por um lado, de sedimentação estrutural e, por outro, de agitação caótica propulsora de devires, através dos quais outros e estranhos "eus" podem vir a existir a partir de novas experiências, com outros contornos, outras linguagens, outras estruturas, outros territórios. A face sedimentar da subjetividade, como composta pelas memórias, afetos, signos e símbolos que ficam marcados como referência subjetiva para a existência dos sujeitos desde o nascimento e que são socialmente compartilhados e aprendidos. No entanto, estas marcas são permanentemente afetadas a cada nova experiência, com maior ou menor intensidade, de acordo

\footnotetext{
Ao passo em que empresas da web se esforçam para fornecer serviços sob medida para nossos gostos pessoais (incluindo notícias e resultados de pesquisa), acontece uma perigosa e não intencional consequência: caímos na cilada dos "filtros-bolha" e não somos expostos às informaçôes que poderiam desafiar ou ampliar nossa visão de mundo. Eli Pariser argumenta vigorosamente que isto, definitivamente, mostrar-se-á um risco para nossa liberdade, nossa autonomia e mesmo para a democracia, ao nos tornar reféns do que as corporaçôes da internet querem que vejamos on-line. A noção de filtros-bolha é desenvolvida e bem apresentada por Eli Pariser no TED Talks de Março de 2011, disponível em: <http://www.ted.com/talks/lang/por_br/eli_pariser_beware_ online_filter_bubbles.html>. Acesso em: 05 ago. 2011.
} 
com a potencialidade de singularização do universo sócio-cultural no qual ocorrem. (ROLNIK, 1997)

Se as TIC operam reconfigurações da experiência da privacidade e dos direitos sexuais de crianças e adolescentes, discutir sobre os limites das políticas de proteção e as possibilidades de emancipação que a internet oferece é discutir também a produção das subjetividades nas geraçôes digitais. Em tempos de imediatismo, de produção, distribuição, consumo e registro instantâneos do dia a dia a através de vídeos, fotos e mensagens eletrônicas, tudo é consumido e descartado em poucos segundos, virando passado em 24 horas ou menos, inclusive a própria história de vida. Ao mesmo tempo, este imediatismo convive com a "eternalização" desta história de vida registrada no universo digital. Fotos, vídeos, relatos, comentários, mensagens, manifestações... Tudo permanece disponível para a multidão de "amigos desconhecidos" on-line. Quem viu, ouviu ou leu e gostou pode registrar para sempre nossos rastros. O conteúdo permanece disponível para (re)utilização e (re)publicação, mesmo quando esquecido pelos próprios protagonistas. As marcas subjetivas explicitadas no ciberespaço passam a ser extensões da subjetividade que servem como máscaras destas novas personas que são assumidas para potencializar as interações on-line. Imediatismo e permanência convivem nas relaçôes sociais mediadas pelas TIC e compóem o processo de subjetivação na contemporaneidade.

As TIC são dispositivos extremamente relevantes na produção de visibilidade das normas, e do normal, tornando os mecanismos de controle cada vez mais íntimos e imateriais. Com a internet, por exemplo, a democratização da vigilância permite que toda a sociedade seja vigiada e se vigie de dentro de suas próprias residências e em tempo real. Com a internet e com o celular, os processos se tornam mais fluidos e se embalam com entretenimento. (ROLNIK, 1997) Ao mesmo tempo em que as TIC operam como dispositivos de vigilância participativa, modelando subjetividades performativas, 
(BRUNO, 2008) acreditamos que podem operar também na perspectiva da emancipação e da participação crítica das novas gerações na construção de suas subjetividades e na reconstrução das instituições. Nas sociedades de controle (DELEUZE, 1992) o corpo não é mais confinado para ser apropriado pela disciplina e normatizado. Os mecanismos disciplinares estão sendo apropriados pelas intimidades, estão incorporados nas visões de mundo e a constante disputa por visibilidade no mundo das celebridades ilustra o quanto as subjetividades estão capturadas e modelizadas. Este processo tem produzido cada vez mais sujeitos modelados, consumidores de identidades e que ilustram uma produção massiva de subjetividades.

Os movimentos de software livre, o financiamento coletivo de projetos colaborativos, iniciativas que reivindicam uma ética hacker para a ampliação da democracia participativa, sites que oferecem novos mecanismos para exercício da cidadania on-line e organizaçóes que militam on-line pela liberdade de expressão atestam caminhos possíveis para fazer ver e falar novas singularidades a partir das TIC como dispositivos inovadores e potencializadores dos direitos humanos, da diversidade e dos processos de singularização. As próprias TIC servem como dispositivos de enfrentamento aos assujeitamentos e como catalisadoras de novas racionalidades que antes não conseguiam chegar a influenciar a esfera pública. A internet, de certo modo, reproduz o mundo da rua (AMADEU, 2010) e permite um novo tipo de interação social, dando poder à diversidade.

As crianças e adolescentes que crescem passeando por estas novas ruas e praças cibernéticas serão mais ou menos sujeitos de sua própria história, dependendo do tipo de apropriação que fizerem das TIC, e talvez seja aí que se encontre o maior poder destas novas geraçôes. Se, por um lado, aprender a usar estes dispositivos pode prescindir da ajuda dos pais e das escolas, por outro, o tipo de sociabilidade que estas gerações terão com o uso intensivo das TIC dependerá dos valores referenciais que conhecerem em suas casas, em suas escolas, nas 
instituições e, especialmente, nas mídias que frequentam. A mídia massiva permanece exercendo seu papel de consolidação dos valores hegemônicos e manutenção das desigualdades que alimentam privilégios e lucros às famílias e corporações que sustentam. Em contrapartida, a escola, as famílias e as organizações da sociedade civil precisam também se apropriar das TIC para produzir e compartilhar outros saberes, empoderar-se para exercer, também na nova esfera pública, a defesa de outros valores que não apenas os do mercado. Em tempos de primazia do interesse egoísta e do cálculo monetário como referências nas mais variadas esferas da existência, a sociedade em rede parece carecer de um mínimo de relações desinteressadas (dádiva) para que possamos ter, apropriando-nos das TIC como dispositivos, passos mais sólidos na construção de uma sociedade efetivamente guiada pelos direitos humanos.

\section{Referências}

ABAD, M. Crítica política das políticas de juventude. In: FREITAS, M. V.; PAPA, F. de C (Org.). Políticas públicas: juventude em pauta. São Paulo: Cortez, 2003.

AMADEU, S. A. Vigiar e punir: comunicação e controle na Internet. In: CGI. br. Pesquisa sobre o uso das tecnologias da informação e da comunicação no Brasil: 2005-2009. São Paulo: Comitê Gestor da Internet, 2010.

BERTEN, A. Dispositif, médiation, créativité: petite génealogie. Hermès. n. 25: Le dispositif: entre usage et concept. Paris: CNRS Éditions, 1999.

BRUNO, F. Monitoramento, classificação e controle nos dispositivos de vigilância digital. Revista FAMECOS, n. 36, p. 10-16, ago., 2008.

- Mapas de crime: vigilância distribuída e participação na cibercultura.

Revista da Associação Nacional dos Programas de Pós-Graduação em

Comunicação | E-compós, Brasília, v. 12, n. 2, maio/ago. 2009, p. 1-16.

- O biopoder nos meios de comunicação: o anúncio de corpos virtuais.

Dossiê Comunicação, mídia e consumo, São Paulo, v. 3 n. 6, p. 63-79, mar. 2006. 
BRUNO, F. e PEDRO, R. Entre Aparecer e Ser: tecnologia, espetáculo e subjetividade contemporânea. In : CONGRESSO BRASILEIRO DE CIENCIAS DA COMUNICAÇÃO, 27., 2005, Rio de Janeiro. Anais... Rio de Janeiro: Intercom , 2005.

BUCKINGHAM, D. (Ed.). Youth, identity, and digital media. Edited by David Buckingham. The John D. and Catherine T. MacArthur Foundation Series on Digital Media and Learning. Cambridge, The MIT Press, 2008.

DELEUZE, G. Foucault. São Paulo: Brasiliense, 1998.

DELEUZE, G. Conversações: 1972-1990. Rio de Janeiro: Ed. 34, 1992.

FOUCAULT, M. Microfísica do poder. Rio de Janeiro: Graal, 1999.

FOUCAULT, Michel. Vigiar e Punir: nascimento da prisão. 29 ed. Petrópolis, RJ:

Editora Vozes, 2004.

GUATTARI, F. Caosmose: um novo Paradigma Estético. Editora 34. Rio de Janeiro: 1992.

KERBAUY, M.T.M. Políticas de juventude: políticas públicas ou políticas governamentais? Estudos de Sociologia, n. 18/19, p.193-203, 1997.

LEMOS, A. \& LEVY, P. O futuro da Internet: em direção à uma ciberdemocracia planetária. São Paulo: Editora Paulus, 2010.

LIVINGSTONE, S. Children and Internet: great expectations, challenging realities. Cambridge: Polity, 2009.

MARTÍN-BARBERO, J. Dos meios às mediações. Rio de Janeiro: Editora da UFRJ, 2001.

MELO, E. R. Direito e norma no campo da sexualidade na infância e na adolescência. In: UNGARETTI, M. A. (Org.). ABMP. Criança e adolescente: direitos e sexualidades. São Paulo: ABMP, 2008.

PEETERS, H. e CHALIER, P. Contribuitions à une théorie du dispositif. Hermès, n. 25. Le dispositif: entre usage et concept. Paris: CNRS Éditions, 1999.

ROLNIK, S. Toxicômanos de identidade: Subjetividade em tempo de globalização. In: LINS, D.(Org.). Cultura e subjetividade: saberes nômades. Papirus: Campinas, 1997, p. 19-24. 